\title{
Targeted use of Alpha Particles: Current Status in Cancer Therapeutics
}

\section{Oliver Sartor ${ }^{3,4,5 *}$, Bassam N Maalouf ${ }^{3,4}$, Carlin R Hauck ${ }^{3}$ and Roger M Macklis ${ }^{1,2}$}

${ }^{1}$ Department of Radiation Oncology, Cleveland Clinic Lerner College of Medicine, USA

${ }^{2}$ Taussig Cancer Center, Cleveland Clinic Lerner College of Medicine, USA

${ }^{3}$ Tulane University School of Medicine, USA

${ }^{4}$ Department of Medicine, Section of Hematology-Oncology, USA

${ }^{5}$ Tulane cancer center, USA

\begin{abstract}
Purpose of review: To summarize the current role of alpha particles in cancer treatment including both clinical and pre-clinical data.

Recent findings: Though discovered more than hundred years ago, no targeted alpha emitters have yet to be approved as a systemic approach to cancer therapy. Until recently, most approaches to target alpha particle emitters utilized conjugation with antibodies through chelators. Limited clinical data are available using this approach; most alpha emitters have been studied in pre-clinical models though ${ }^{213}$ bismuth has been studied in leukemic patients. The novel alpha emitter ${ }^{223}$ radium has been studied more extensively than other agents in this class and a recent large randomized phase III trial data with ${ }^{223}$ radium demonstrates overall survival benefit in castrate resistant prostate cancer patients with skeletal metastasis.
\end{abstract}

Summary: The alpha emitter ${ }^{223}$ radium is expected to play a significant future role in therapy for bone-metastatic disease and a variety of novel alpha emitters offer the potential for targeted therapy via conjugation with specific antibodies or targeted nanoparticles.

Keywords: Cancer therapy; Alpha particles; Radium; Bone; Prostate cancer

\section{Historical Background}

Roentgen's discovery of electrically generated $\mathrm{x}$-rays in 1895 was soon followed in 1897 by Becquerel's description of a similar natural phenomenon produced by potassium uranyl sulfate. For her doctoral dissertation, Marie Curie investigated whether other heavy elements might possess similar capabilities. In 1898 Marie, with the aid of her husband Pierre Currie, discovered the existence of radium and polonium and after four years of hard work were rewarded by one tenth gram of pure radioactive radium salts. They would both share the physics Nobel Prize in 1903 with A. Henri Becquerel. Pierre Curie was appointed to the chair of physics at the Sorbonne in 1904, and Marie continued her efforts with her assistant Andre Debierne to isolate pure, non-chloride radium. After her husband was killed in an accident in the Paris streets, Marie Curie was appointed to his seat at the Sorbonne. In 1910, with Debierne, she finally succeeded in isolating pure, metallic radium and was the sole recipient of the 1911 Nobel Prize in chemistry for that achievement, making her the first person to win a second Nobel Prize [1,2]. Bell suggested for the first time using radium for tumor therapy [3]. Further suggestions followed for its use in multiple medical illnesses including infectious, inflammatory issues as well as malignant conditions [3-5].

Thorotrast was used as a contrast medium for radiological procedures in the 1930s. This agent's use was not linked to radioactive properties but it contained ${ }^{232}$ thorium, an alpha emitter. Though there were no immediate adverse events, it was later recognized that this agent was unfortunately associated with markedly increased risk of liver, biliary tract cancers, and leukemia [6]. ${ }^{213} \mathrm{Bi}$ was the first alpha emitter to be used in modern human clinical trials in 1997 [7], but it is likely that ${ }^{223} \mathrm{Ra}$ will be the first systemic targeted alpha emitter approved by regulatory agencies for human use.

\section{Alpha Emitter Radiobiology}

The primary benefit of targeted alpha particle therapy is the ability to deliver radiation in a highly localized manner [8]. Typical alpha particles have a range in tissue of only a few cell diameters $50-90 \mu \mathrm{m}$ [9]. Thus, if delivery to cancerous cells is achieved, there is lower risk of healthy cells being caught in the radiation crossfire. The linear energy transfer (LET) of alpha particles, approximately $25-230 \mathrm{kEv} / \mu \mathrm{m}$, is about 100 to 1000 times greater than the average LET of beta particles [8]. This higher LET results in a greater potential for biologic damage by alpha particles as compared to beta particles and other lower LET radiations. Combined, the small range and high LET of alpha particles allow for a relatively focal radiation therapy high potency with the radionuclide quite-precisely to the region of interest [10].

DNA double strand breaks are considered the major clinically relevant lesions caused by alpha particle radiation. These breaks result in chromosome aberrations and impairment of the reproductive integrity of a cell. The double strand breaks created by alpha particle radiation have been found to be highly complex, more resistant to normal repair, and thus more genotoxic than double strand breaks caused by other modalities [11]. This is thought to be due to alpha particles tendency to create dense tracks of ionization that create clusters of DNA damage, whereas the damage caused by gamma radiation is more sparsely distributed [12]. The maximum rate of double-stranded DNA breaks occurs at LETs of $100-200 \mathrm{keV} / \mu \mathrm{m}$, a range that includes the LET of most alpha particles [13]. Low LET radiation, including gamma

*Corresponding author: Oliver Sartor, Laborde Professor of Cancer Research, Tulane Cancer Center, New Orleans, Louisiana, USA, Tel: +504 988 7869; Fax +504 988 5059; E-mail: osartor@tulane.edu

Received July 12, 2012; Accepted August 02, 2012; Published August 22, 2012

Citation: Sartor O, Maalouf BN, Hauck CR, Macklis RM (2012) Targeted use of Alpha Particles: Current Status in Cancer Therapeutics. J Nucl Med Radiat Ther 3:136. doi:10.4172/2155-9619.1000136

Copyright: ( 2012 Sartor O, et al. This is an open-access article distributed under the terms of the Creative Commons Attribution License, which permits unrestricted use, distribution, and reproduction in any medium, provided the original author and source are credited. 
radiation, has been found to cause a prolonged arrest of the cell cycle in G1 and G2, which allows the cells time to repair DNA damage. The cell cycle arrest caused by alpha particle radiation is shorter, and more difficult to repair, thus alpha particles are more effective at inducing cellular death [12].

In addition to directly damaging DNA, alpha particles have been demonstrated to cause chromosomal instability even in the descendants of non-irradiated stem cells in the vicinity of irradiated cells. This 'bystander effect' reflects the potential for interaction between irradiated and non irradiated cells in the production of genetic damage [14].

\section{Radionuclides of Potential Clinical Interest}

The specific radiobiologic properties of some of the most important alpha emitters with potential use in clinical medicine are briefly discussed below and summarized in table 1 .

\section{${ }^{149}$ Terbium (Tb)}

Bombarding ${ }^{141}$ Praseodymium (Pr) with $14 \mathrm{~N}$ ions will result in ${ }^{149} \mathrm{~Tb}$ production. With a half life of 4 hours, it is a lanthanide that decays via a complicated set of mechanisms: $\alpha$-decay (17\%), $\beta+$-decay $(4 \%)$, and electron capture $(79 \%)[15,16]$. It has been conjugated to antibodies and used in mice with colorectal cancer, melanoma as well as other malignancies $[17,18]$. When compared to ${ }^{213} \mathrm{Bi}$ in preclinical studies the results were indecisive [19].

\section{${ }^{211}$ Astatine (At)}

Using cyclotron beam irradiation ${ }^{211} \mathrm{At}$ is produced via ${ }^{209} \mathrm{Bi}$ and then isolated by dry distillation procedure. It has a half life of 7.2 hours and the alpha particles emitted have a mean energy of $6.8 \mathrm{MeV}$ with a mean LET of $97-99 \mathrm{keV} / \mu \mathrm{m}$. Its daughter, ${ }^{211}$ Polonium (Po), emits $\mathrm{x}$-rays and can be used in external imaging for bio-distribution studies [20]. Preclinical studies have shown that mice receiving more than 300 $\mathrm{kBq}$ of ${ }^{211} \mathrm{At}$ had increased incidence of lymphomas and plasmacytomas $[21,22] .{ }^{211}$ At has been studied on mice with melanoma [23]. Its use in clinical trial has been limited and described briefly below.

\section{${ }^{212}$ Bismuth (Bi)}

${ }^{212} \mathrm{Bi}$ is an alpha emitting radioisotope produced via ${ }^{224}$ Radium generator system with a short physical half life of 60.55 minutes and decays to stable ${ }^{208} \mathrm{~Pb}$ (lead) with a mean energy of $7.83 \mathrm{MeV}$. Non targeted radiotherapy with ${ }^{212} \mathrm{Bi}$ did not deliver appropriate alpha radiation to specific tissues [24-26].

\section{${ }^{213}$ Bismuth}

The parent radionuclide for making ${ }^{213} \mathrm{Bi}$ generators is ${ }^{225}$ actinium, which is a decay product of ${ }^{229}$ thorium. They are all members of the decay chain of ${ }^{237}$ Neptunian $(\mathrm{Np}) .{ }^{213} \mathrm{Bi}$ has a half-life of 45.6 minutes and emits an alpha particle of $8 \mathrm{MeV}$. Additionally, a $440 \mathrm{keV}$ photon emission accompanies $26.5 \%$ of ${ }^{213} \mathrm{Bi}$ decays, allowing detailed biodistribution and dosimetry studies to be performed [19,24,26].

\section{${ }^{225}$ Actinium (Ac)}

${ }^{225} \mathrm{Ac}$, the mother of ${ }^{213} \mathrm{Bi}$, can be produced by decay of ${ }^{223} \mathrm{U}$ or by accelerator based methods. It has 10 days half life and may have more potent effects on cancer cells as compared to ${ }^{213} \mathrm{Bi}[27,28]$. In order to optimize the therapeutic potential this molecule has been linked to antibodies to allow specific cell targeting but even with the most attempts to deliver a stable internalization, a significant release of alpha emitting daughters was encountered causing toxicity with radiation nephropathy being a particular issue [28-30].

\section{${ }^{223}$ Radium (Ra)}

${ }^{226} \mathrm{Ra}$ bombardment by neutron irradiation will result in ${ }^{227} \mathrm{Ac}$ production that after purification and elution with nitric oxide results in ${ }^{227} \mathrm{Th}$ formation. Further elution will result in pure ${ }^{223} \mathrm{Ra}$ formation. ${ }^{223} \mathrm{Ra}$ half-life is 11.4 days; it decays through a cascade of short-lived alpha- and beta-emitting progeny with the emission of about $28 \mathrm{MeV}$ of energy per starting atom. Four alpha particles and two beta particles are emitted (Figure 1). The primary alpha particles emitted by ${ }^{223} \mathrm{Ra}$ are 5.61 and $5.72 \mathrm{MeV}$. The first daughter in the ${ }^{223} \mathrm{Ra}$ decay pathway is ${ }^{219} \mathrm{Radon}$, a gaseous product that would pose a serious challenge to control in vivo [31,32]. When ${ }^{223} \mathrm{Ra}$ is given at high doses $(>185 \mathrm{kBq} /$ $\mathrm{kg}$ ) to rats it resulted in animal death secondary to hemorrhage but with lower doses (60 to $110 \mathrm{kBq} / \mathrm{kg}$ ) it exhibited significant anti-tumor activity in certain model systems and was fairly tolerated [32-34]. When compared to a beta emitter ${ }^{89} \mathrm{Sr}{ }^{223} \mathrm{Ra}$ had more skeletal uptake [35]. It is mostly cleared by direct excretion in the intestines. ${ }^{223} \mathrm{Ra}$ is the most alpha emitter to draw attention in clinical trials.

\section{Targeted Radioimmunotherapy}

Multiple approaches using monoclonal antibodies, immunotoxins, and radioimmunoconjugates have emerged as projected strategies for the treatment of various cancers [36-43]. Most clinical radio immunotherapy studies, and all the FDA approved products, have used beta-emitting isotopes. Because of their comparatively long range in tissue $(0.8-5 \mathrm{~mm})$, beta particles create a prominent cytotoxic effect leading not only to the destruction of targeted cells and surrounding tumor cells but also the killing of normal bystander cells potentially producing a higher risk of toxicity. As noted above, alpha particles have path lengths of only 50 to $80 \mu \mathrm{m}$ and the LET for a particles is up to 500 times greater than that of beta particles $(100 \mathrm{keV} / \mu \mathrm{m}$ vs. $0.2 \mathrm{keV} / \mu \mathrm{m})$ [44]. Injured cells have limited capacity to repair DNA damage induced by alpha particles, and cell death may result from a single atomic decay traversing the nucleus [45]. Therefore, radioimmunotherapy with a particle-emitting isotopes may produce more efficient killing of individual tumor cells with little damage to surrounding normal tissues. The specificity and efficacy of targeted $\alpha$ particle immunotherapy with ${ }^{212} \mathrm{Bi},{ }^{213} \mathrm{Bi}$, and ${ }^{211} \mathrm{At}$ have been reported in several experimental models. Table 2 shows summary of radionuclides used in human studies.

In order to utilize alpha-emitting radionuclide in an immunotherapeutic fashion, they must first be attached to

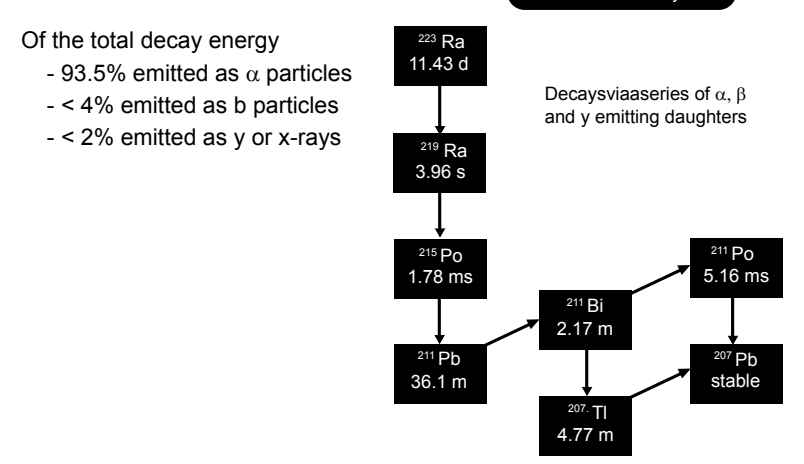

Figure 1: Radium Decay Chain. 
Citation: Sartor O, Maalouf BN, Hauck CR, Macklis RM (2012) Targeted use of Alpha Particles: Current Status in Cancer Therapeutics. J Nucl Med Radiat Ther 3:136. doi:10.4172/2155-9619.1000136

Page 3 of 8

\begin{tabular}{|c|c|c|c|c|c|}
\hline Radionuclide & Daughters & Half life & Emitted Particles & Percent emitted per decay & Particle Energy (keV) \\
\hline \multirow[t]{25}{*}{${ }^{149} \mathrm{~Tb}$} & & $4.2 \mathrm{~h}$ & $\alpha$ & 17 & 4078 \\
\hline & & & Y & 61 & 43 \\
\hline & & & Y & 11 & 48 \\
\hline & & & Y & 28 & 165 \\
\hline & & & Y & 33 & 352 \\
\hline & & & Y & 20 & 388 \\
\hline & & & Y & 17 & 652 \\
\hline & & & Y & 12 & 817 \\
\hline & & & Y & 16 & 853 \\
\hline & & & e- & 30 & 7 \\
\hline & & & e- & 20 & 8 \\
\hline & & & e- & 10 & 115 \\
\hline & ${ }^{149} \mathrm{Gd}$ & $9.25 \mathrm{~d}$ & $Y$ & 82 & 41 \\
\hline & & & Y & 15 & 47 \\
\hline & & & Y & 42 & 150 \\
\hline & & & Y & 23 & 299 \\
\hline & & & Y & 18 & 347 \\
\hline & & & e- & 53 & 7 \\
\hline & & & e- & 40 & 8 \\
\hline & & & e- & 17 & 30 \\
\hline & & & e- & 21 & 101 \\
\hline & ${ }^{149} \mathrm{Eu}$ & $93 d$ & $\mathrm{Y}$ & 96 & 40 \\
\hline & & & Y & 12 & 45 \\
\hline & & & e- & 55 & 7 \\
\hline & ${ }^{145} \mathrm{Eu}$ & $59 d$ & Y & 17 & 894 \\
\hline \multirow[t]{7}{*}{${ }^{211} \mathrm{At}$} & & $7.2 \mathrm{~h}$ & $\alpha$ & 42 & 5982 \\
\hline & & & Y & 19 & 80 \\
\hline & ${ }^{211} \mathrm{Po}$ & $516 \mathrm{~ms}$ & $\alpha$ & 58 & 7594 \\
\hline & ${ }^{207} \mathrm{Bi}$ & 32 y & Y & 24 & 70 \\
\hline & & & Y & 41 & 570 \\
\hline & & & Y & 31 & 1 \\
\hline & ${ }^{207} \mathrm{~Pb}$ & stable & & & \\
\hline \multirow[t]{7}{*}{${ }^{212} \mathrm{Bi}$} & & $60.6 \mathrm{~min}$ & $\alpha$ & 36 & 6207 \\
\hline & & & $\beta-$ & 64 & 771 \\
\hline & ${ }^{212} \mathrm{Po}$ & & $\alpha$ & 64 & 8954 \\
\hline & ${ }^{208} \mathrm{TI}$ & & $\beta-$ & 36 & 560 \\
\hline & & & Y & 8 & 510 \\
\hline & & & Y & 31 & 590 \\
\hline & & & Y & 36 & 2600 \\
\hline \multirow[t]{7}{*}{${ }^{213} \mathrm{Bi}$} & & $46 \min$ & $\alpha$ & 2 & 5982 \\
\hline & & & $\beta-$ & 98 & 444 \\
\hline & & & Y & 17 & 440 \\
\hline & ${ }^{213} \mathrm{Po}$ & $4.2 \mu \mathrm{s}$ & $\alpha$ & 98 & 8537 \\
\hline & ${ }^{209} \mathrm{TI}$ & $2.2 \mathrm{~min}$ & $\beta-$ & 2 & 659 \\
\hline & ${ }^{209} \mathrm{~Pb}$ & $3.25 \mathrm{~h}$ & $\beta-$ & 100 & 198 \\
\hline & ${ }^{209} \mathrm{Bi}$ & stable & & & \\
\hline \multirow[t]{12}{*}{${ }^{223} \mathrm{Ra}$} & & $11.4 \mathrm{~d}$ & $\alpha$ & 100 & 5979 \\
\hline & & & Y & 100 & 80 \\
\hline & & & Y & 10 & 270 \\
\hline & ${ }^{219} \mathrm{Rn}$ & $32.3 \mathrm{~ms}$ & $\alpha$ & 100 & 6949 \\
\hline & & & Y & 10 & 270 \\
\hline & ${ }^{215} \mathrm{Po}$ & $1.8 \mathrm{~ms}$ & $\alpha$ & 100 & 7526 \\
\hline & ${ }^{211} \mathrm{~Pb}$ & $36.1 \mathrm{~min}$ & $\beta-$ & 100 & 447 \\
\hline & ${ }^{211} \mathrm{Bi}$ & $2.1 \mathrm{~min}$ & $\alpha$ & 16 & 6278 \\
\hline & & & $\alpha$ & 84 & 6623 \\
\hline & & & Y & 13 & 350 \\
\hline & ${ }^{207} \mathrm{TI}$ & $4.8 \mathrm{~min}$ & $\beta-$ & 100 & 493 \\
\hline & ${ }^{207} \mathrm{~Pb}$ & stable & & & \\
\hline \multirow[t]{2}{*}{${ }^{225} \mathrm{Ac}$} & & $10 \mathrm{~d}$ & $\alpha$ & 100 & 5935 \\
\hline & ${ }^{221} \mathrm{Fr}$ & $4.9 \mathrm{~min}$ & $\alpha$ & 100 & 6458 \\
\hline
\end{tabular}




\begin{tabular}{|c|c|c|c|c|c|c|c|}
\hline & & & $\mathrm{Y}$ & 10 & & & 218 \\
\hline & ${ }^{217} \mathrm{At}$ & & $\alpha$ & 100 & & & 7201 \\
\hline & ${ }^{213} \mathrm{Bi}$ & $46 \mathrm{~min}$ & $\alpha$ & 2 & & & 5982 \\
\hline & ${ }^{213} \mathrm{Po}$ & $4.2 \mu \mathrm{s}$ & $\alpha$ & 98 & & & 8537 \\
\hline & ${ }^{209} \mathrm{TI}$ & $2.2 \mathrm{~min}$ & $\beta-$ & 2 & & & 659 \\
\hline & ${ }^{209} \mathrm{~Pb}$ & $3.25 \mathrm{~h}$ & $\beta-$ & 100 & & & 198 \\
\hline & ${ }^{209} \mathrm{Bi}$ & stable & & & & & \\
\hline${ }^{227} \mathrm{Th}$ & & $18.7 \mathrm{~d}$ & $\alpha$ & 100 & & & 6146 \\
\hline & ${ }^{223} \mathrm{Ra}$ & $11.4 \mathrm{~d}$ & $\alpha$ & 100 & & & 5979 \\
\hline & & & Y & 100 & & & 80 \\
\hline & & & Y & 10 & & & 270 \\
\hline & ${ }^{219} \mathrm{Rn}$ & $32.3 \mathrm{~ms}$ & $\alpha$ & 100 & & & 7946 \\
\hline & & & Y & 10 & & & 270 \\
\hline & ${ }^{215} \mathrm{Po}$ & $1.8 \mathrm{~ms}$ & $\alpha$ & 100 & & & 7526 \\
\hline & ${ }^{211} \mathrm{~Pb}$ & $36.1 \mathrm{~min}$ & $\beta-$ & 100 & & & 447 \\
\hline & ${ }^{211} \mathrm{Bi}$ & $2.1 \mathrm{~min}$ & $a$ & 16 & & & 6278 \\
\hline & & & $\alpha$ & 84 & & & 6623 \\
\hline & & & Y & 13 & & & 350 \\
\hline & ${ }^{207} \mathrm{TI}$ & $4.8 \mathrm{~min}$ & $\beta-$ & 100 & & & 493 \\
\hline & ${ }^{207} \mathrm{~Pb}$ & stable & & & & & \\
\hline & & & & le 1: Adapted from McDevitt et & I. [44]. & & \\
\hline Radionuclide & Linker & Trial/\# & ents & Disease/endpoint & Results & survival & Author \\
\hline${ }^{211} \mathrm{At}$ & 81-C6 & Phase & & $\begin{array}{l}\text { Primary brain tumors/dose } \\
\text { finding }\end{array}$ & $\begin{array}{l}\text { No grade } 3 \\
\text { toxicity }\end{array}$ & $\begin{array}{l}\text { OS: } 54 \text { weeks } \\
\text { for GBM }\end{array}$ & Zalutsky et al. [60] \\
\hline${ }^{211} \mathrm{At}$ & MX35 F(ab)2 & Phase & & $\begin{array}{l}\text { Ovarian carcinoma/ dose } \\
\text { absorption, safety }\end{array}$ & $\begin{array}{l}\text { No adverse } \\
\text { events }\end{array}$ & Not assessed & Andersson et al. [64] \\
\hline${ }^{213} \mathrm{Bi}$ & HuM195 & Phase & & AML & RR:14/18 no & & Jurcic et al. [7] \\
\hline${ }^{213} \mathrm{Bi}$ & HuM195 & Phase & & $\begin{array}{l}\text { AML sequential with ara-c/ } \\
\text { dose finding ,response rate }\end{array}$ & $\begin{array}{l}\text { Limiting mye } \\
\text { high dose/co } \\
\text { only with } 2 \mathrm{~h}\end{array}$ & $\begin{array}{l}\text { supression with } \\
\text { plete response } \\
\text { nest doses }\end{array}$ & Rosenblat et al. [52] \\
\hline${ }^{213} \mathrm{Bi}$ & Anti CD-20 & Phase & & $\mathrm{NHL} /$ Dose finding & Only 3 treate & abstract form & Heeger et al. [53] \\
\hline${ }^{213} \mathrm{Bi}$ & 9.2 .27 & Phase & & $\begin{array}{l}\text { Metastatic melanoma/ safety } \\
\text { efficacy }\end{array}$ & $\begin{array}{l}\text { Safe up to } 4 \\
\text { at } 200 \mathrm{mCi}\end{array}$ & $\mathrm{mCi}$ efficacious & Allen et al. [56] \\
\hline
\end{tabular}

OS: overall survival; CR: complete remission; RR: response rate; GBM: glioblastoma multiforme; NHL: non Hodgkin lymphoma; AML: acute myeloid leukemia

Table 2: Radionuclides and linkers used in human studies.

monoclonal antibodies via a linking molecule. Such molecules can serve multiple purposes, the most basic of which is allowing attachment of the monoclonal antibody and radionuclide to form the radioimmunoconjugate. These linking molecules can be designed as bifunctional molecules to also increase the stability of the final product in vivo, decrease potential toxicity to the target organs, and allow for more rapid clearance from the blood. When injected intravenously, ${ }^{225} \mathrm{Ac}$ is extremely toxic, depositing primarily in the liver, bone, kidney and heart, and being cleared very slowly, with up to $50 \%$ of a dose remaining in the body at 6 months after injection [46]. In an attempt to reduce its toxicity, ${ }^{225} \mathrm{Ac}$ has been 'trapped' within chelators that allow for its increased excretion from the body. Initial efforts resulted in the conjugation of ${ }^{225} \mathrm{Ac}$ to available chelators including Ethylene Diamine Tetraacetic Acid (EDTA), Cyclohexyl Diethylenetriamine Pentaacetic Acid (CHX-DTPA) and 1,4,7,10,13-Pentaazacyclopentadecane-N, N', N", N"', N'"'-Pentaacetic Acid (PEPA). Each chelator allowed for reduced organ accumulation of ${ }^{225} \mathrm{Ac}$, with CHX-DTPA and PEPA providing a 75\% improvement over EDTA [46]. However, even with this decrease in tissue deposition, the level of organ toxicity was still unacceptably high, particularly in the liver. Further investigation into other potential chelators revealed 1,4,7,10,13,16-Hexaazocyclooctadecane-N,N',N",N"',N"','N"','Hexaacetic Acid, (HEHA) to be a stable carrier of ${ }^{225} \mathrm{Ac}$, which also allowed for the most rapid clearance and lowest accumulation within the liver, bone, kidneys and heart [46]. HEHA has been synthesized, radiolabeled to ${ }^{225} \mathrm{Ac}$, and conjugated to three different monoclonal antibodies with reasonable yields thus providing a reasonable approach to targeted alpha particles via radioimmunotherapy [30].

There has been less investigation into potential radioimmunoconjugate linking molecules for ${ }^{227} \mathrm{Th}$ than for ${ }^{225} \mathrm{Ac}$, however ${ }^{227} \mathrm{Th}$ has been linked by p-benzyl-DOTA to rituximab. The resulting compound is stable, with a similar retention time and immunoreactivity to unlabeled rituximab [30]. Compared to free thorium, ${ }^{227} \mathrm{Th}$-p-nitrobenzyl-DOTA had a lower uptake and increased clearance in all organs studied except for the large intestines. Free thorium deposits predominantly in bone, and the uptake in the bone of ${ }^{227} \mathrm{Th}$-p-nitrobenzyl-DOTA has been demonstrated to be seven times lower than that of free thorium [30]. Subsequent efforts have also succeeded in creating a similar radioimmunoconjugate by binding ${ }^{227} \mathrm{Th}$ to trastuzumab via p-iso-thiocyanato-benzyl-DOTA [29,47-49].

\section{ClinicalTrials InvolvingAlphaRadioimmunoconjugates}

\section{Hematologic malignancies}

Patients with recurrent and refractory leukemia have very limited treatment options with allogenic stem cell transplant being the only curative treatment option but a large number of them have no eligible donor and other available therapy results in remissions in a small percentage and that remission is usually short lived. 
The concept of antibody mediated therapy has played a major role in hematologic malignancies in the past few years. The humanized anti CD33 antibody HuM195 have been used in relapsed acute myeloid leukemia with minimal overall response and complete response achieved only in patients with low disease bulk [50], to increase the potency of above antibodies conjugation with targeted radiotherapy offers a particular strategy that helps overcoming tumor antigen heterogeneity. The choice of the appropriate isotope depends on its half life, biologic properties and ability to provide the maximum treated effect with minimal possible toxicity.

While beta emitters long range activity can result in major target cell killing, it can also be associated with bystander normal cell killing. To avoid that linking HuM195 to alpha emitters sounded more appealing and this prompted Sgouros et al. [7] to conduct a phase I trial conjugating HuM195 to ${ }^{213} \mathrm{Bi}$ after encouraging preclinical activity. The above trial was a dose finding and safety assessment of ${ }^{213} \mathrm{Bi}-\mathrm{HuM} 195$ showing that the absorbed dose ratio between marrow, liver and spleen volumes and the whole body for ${ }^{213} \mathrm{Bi}-\mathrm{HuM} 195$ is 1000 -fold greater than that commonly observed with beta-emitting radionuclide used for radioimmunotherapy $[7,51]$. Seventeen patients with AML and one patient with CMML were treated with escalated radioactivity doses of ${ }^{213} \mathrm{Bi}-\mathrm{HuM} 195$. A bone marrow assessment was done seven to ten days as well as 4 weeks after treatment. Fourteen (93\%) of 15 evaluable patients had reductions in peripheral blood leukemia cells, and $14(78 \%)$ of the 18 patients had reductions in the percentages of bone marrow blasts. There was no complete remission. Maximum tolerated dose in this study was not reached because escalation beyond $37 \mathrm{MBq} / \mathrm{kg}$ was restricted by the availability and cost of ${ }^{225} \mathrm{Ac}$. There was no infusionrelated toxicity. Grade 1 liver function abnormalities were seen in 4 patients $(22 \%)$. Two patients (11\%) had grade 2 hyperbilirubinemia. The above abnormalities resolved within 3 to 14 days. Thirteen (76\%) of the 17 patients developed grade $3(n=2)$ or $4(n=11)$ leucopenia; however, substantial clearing of circulating blasts (more than 95\%) accounted for this finding in 11 patients (85\%). Dose-limiting toxicity, defined as grade 4 leucopenia for more than 35 days from the start of therapy, was seen in one patient treated at the $37 \mathrm{MBq} / \mathrm{kg}$ dose level following relapse after allogenic bone marrow transplant [51].

The prior findings support the feasibility and safety of ${ }^{213} \mathrm{Bi}$ HuM195 in patients with leukemia but it is likely to be more beneficial in patients with low residual disease.

The above results triggered Rosenblat et al. [52] to use ${ }^{213} \mathrm{Bi}$ HuM195 after partially debulking AML (Acute Myeloid Leukemia) patients with cytarabine. Thirty one patients with AML were treated with cytarabine $200 \mathrm{mg} / \mathrm{m}^{2}$ daily for 5 days followed by ${ }^{213} \mathrm{Bi}-\mathrm{HuM} 195$ at dose ranging from 18.5 to $46.25 \mathrm{MBq} / \mathrm{kg}$. Thirteen patients had untreated AML ( 5 with de novo AML; 8 with secondary AML). Fifteen patients had relapsed AML, and 3 patients had primary refractory AML. Fifteen patients were treated in the phase I portion of the trial: 3 patients each received 18.5 and $27.75 \mathrm{MBq} / \mathrm{kg}, 5$ received $37 \mathrm{MBq} / \mathrm{kg}$, and 4 were treated with $46.25 \mathrm{MBq} / \mathrm{kg}$. An additional 16 patients were enrolled in the phase II portion of the study [52].

Myelosuppression was the most common observed toxicity with grade 3-4 neutropenia in 9 patients. Twenty patients (65\%) had documented bacterial infections, 19 patients (61\%) developed presumed fungal pneumonia. Mortality related to infectious complications occurred in 2 of 21 patients (10\%) receiving $37 \mathrm{MBq} /$ $\mathrm{kg}$ and in 1 of 4 patients (25\%) treated with $46.25 \mathrm{MBq} / \mathrm{kg}$. Transient grade $3 / 4$ liver function abnormalities were seen in five patients (16\%). Twenty six of 31 patients had interpretable bone marrow aspirations 4 or 8 weeks after the start of therapy. Among them, 20 (77\%) had $>20 \%$ decrease in marrow blasts. There was no response in patients receiving $<37 \mathrm{MBq}$. Out of the 11 patients with untreated AML who received doses greater than or equal to minimal treatment dose, 2 achieved complete response, 1 achieved complete response with incomplete platelet recovery, and 2 achieved partial response. None of the seven patients with primary refractory AML or multiply treated relapsed disease responded making initial successful debulking a condition to acceptable ${ }^{213} \mathrm{Bi}-\mathrm{HuM} 195$ benefit [52].

The introduction of anti-CD20 antibodies (rituximab) have revolutionized treatment modalities in non Hodgkin lymphoma leading to its incorporation in most B-cell lymphomas treatment regimens but unfortunately its use in indolent lymphoma has not resulted in major maintained complete response and refractory and relapsing cases continues to offer a challenge.

The biologic properties of alpha emitters described in detailed above offer potential theoretical advantages over beta emitters. Multiple alpha emitters have been conjugated to rituximab including ${ }^{213} \mathrm{Bi}$, ${ }^{211} \mathrm{At}$ and ${ }^{227} \mathrm{Th}$ in vitro and have shown efficacy in multiple preclinical trials in non Hodgkin lymphoma. In a first phase I dose escalation trial initiated to determine the safety and efficiency of ${ }^{213} \mathrm{Bi}$-labelled anti-CD20 antibodies nine patients with relapsed or refractory non Hodgkin lymphoma were treated in three dose groups with activities of 555 to $1591 \mathrm{MBq}^{213} \mathrm{Bi}$ coupled to $3 \mathrm{mg}$ of the anti-CD20 antibody Rituximab. No acute toxicities and no extramedullary toxicity were seen, but mild leucopenia was observed in two patients [53]. The same concept has also been validated in multiple myeloma preclinical studies using ${ }^{213} \mathrm{Bi}$.

\section{Solid tumor excluding prostate}

Radiolabeled antibody therapy has been less successful in the treatment of solid tumors than hematological tumors and bony metastases. Solid tumors tend to be less permeable and provide a physical barrier to antibody penetration. The therapeutic effect of radiolabeled antibodies is thus dependent on the tumor's vascular supply, as a means to infiltrate the solid tumor [54]. The melanomaassociated chondroitin sulfate proteoglycan (MCSP) is a human protein, widely expressed in melanoma vasculature that is being tested as a target for radioimmunologic therapy in phase 1 trials. A murinederived monoclonal antibody, known as 9.2.27 Mab, is specific to MCSP. When conjugated to ${ }^{213} \mathrm{Bi}$, it has been shown to be lethal to melanoma cells in humans, while sparing normal tissue [55]. A phase 1 study in which ${ }^{213} \mathrm{Bi}-9.2 .27$ was injected directly into the tumors of 16 patients with stage IV melanoma, demonstrated significant tumor cell death at doses well below the maximum tolerated dose [56]. The utility of all radionuclide therapies depend on the ratio of the lethal tumor dose to the dose needed to cause damage to critical organs. ${ }^{213} \mathrm{Bi}$ is known to accumulate in the kidneys, however this was not demonstrated in the trial, indicating that the radionuclide did not significantly dissociate from the antibody before the compound's excretion [56].

The treatment of malignant gliomas with the alpha-emitting radionuclide ${ }^{213} \mathrm{Bi}$ has also progressed to stage 1 clinical trial. WHO grade II-IV gliomas overexpress the transmembrane neurokinin type-1 receptor (NK-1). Substance P is the physiological ligand of NK-1, and has been coupled to ${ }^{213} \mathrm{Bi}$ for use as a therapeutic radioimmunoconjugate. In a five-patient pilot trial, ${ }^{213} \mathrm{Bi}$-DOTA-substance $\mathrm{P}$ was administered directly into the tumors via implanted catheters. After treatment with ${ }^{213} \mathrm{Bi}$-Substance $\mathrm{P}$, each patient's tumor showed radionecrosis on imaging without associated toxicity to normal tissue, and four of the five participants exhibited clinical improvement. Small gliomas 
were the most successfully treated, likely due to a more homogenous distribution of the radionuclide throughout the tumor [57]

Trastuzumab is a humanized monoclonal antibody which has been established as an effective treatment for breast cancer that overexpresses the human epidermal growth factor receptor-2 (HER-2/neu). ${ }^{227} \mathrm{Th}$, when coupled to Trastuzumab, has been demonstrated to have a highly toxic effect against individual tumor cells in vitro, decreasing survival, inhibiting growth and inducing apoptosis in HER2-overexpressing cells [58]. In a preclinical study, mice implanted with HER-2-positive breast cancer xenografts were intravenously injected with ${ }^{227} \mathrm{Th}$-Trastuzumab. Mice treated with $\mathrm{Th}^{227}$-Trastuzumab demonstrated a dose-dependent increase in survival compared to those in the control group, with mean survival time nearly doubling with the administration of the highest dose, $600 \mathrm{kBq} / \mathrm{kg}$ [59]. When a ${ }^{227} \mathrm{Th}$ atom decays into its daughter nuclides, it detaches from Trastuzumab, and loses its anchor to the HER2-expressing tumor cell. Thus, over time, the radioactivity present in non-target tissues, particularly bone, will rise, which may create an interesting opportunity to potentially treat breast cancer patients at risk of developing bone metastases. The half life of ${ }^{227} \mathrm{Th}$ is 18.7 days and thus allows for the excretion of a large fraction of ${ }^{227} \mathrm{Th}$-trastuzumab before free ${ }^{223} \mathrm{Ra}$ can be released into the circulation. The primary toxicity of ${ }^{227} \mathrm{Th}$-trastuzumab treatment is a reversible bone marrow depression [58]. The treatment of breast cancer with alpha emitting radionuclides has not yet progressed to clinical trials, except in the case of skeletal metastasis. An ongoing clinical trial currently recruiting patients addressing the safety of ${ }^{212} \mathrm{~Pb}$ (lead-212)-TCMC-Trastuzumab in patients with Her-2 expressing tumors (ovarian, pancreatic, colon, gastric, endometrial, or breast) having mostly intra-abdominal disease (NCT01384253).

\section{Emphasis on prostate cancer and skeletal metastasis}

Castrate resistant prostate cancer is very likely to involve bone during the course of disease resulting in death and multiple skeletal related events (SREs) including pain, pathological fractures and spinal cord compression. Bone targeted agents such as bisphosphonates (zoledronate), RANKL (Receptor activator of nuclear factor kappa-B ligand) inhibitors (denosumab), and bone-seeking radioisotopes (e.g. ${ }^{89} \mathrm{Sr}$ and ethylenediaminetetramethylene phosphonate (EDTMP)${ }^{153} \mathrm{Sm}$ ) are FDA approved but none of these agents have shown to improve survival in clinical trials.

BSRs (bone seeking radiopharmaceuticals) have been used in osteoblastic bone metastatic by targeting both the tumor cells and the surrounding matrix, currently two BSRs $\left({ }^{89} \mathrm{Sr},{ }^{153} \mathrm{Sm}\right)$ are FDA approved for bone pain palliation and they are both beta emitters.

As briefly described above there were limited clinical trial involving most alpha emitting radionuclides and targeting was primarily via immunoconjugatges. ${ }^{223} \mathrm{Ra}$ targets the osteoid to newly formed bone and thus targets regions of osteoblastic metastases by acting as calcium mimetic (similar to ${ }^{89} \mathrm{Sr}$ ).

The first clinical experience with ${ }^{223} \mathrm{Ra}$ in treatment of skeletal metastasis was described by Nilsson $S$ et al. where fifteen patients with prostate cancer and ten with breast cancer (all with skeletal metastasis) were divided in five different groups of five patients each receiving different dose of ${ }^{223} \mathrm{Ra}$ in a phase one trial addressing safety and tolerability [60]. Pain relief was reported by $52 \%, 60 \%$, and $56 \%$ of the patients after 7 days, 4 weeks and 8 weeks, respectively. Nausea and vomiting was observed more in the highest dosage group. Median survival was around 20 months [61].
The first randomized placebo controlled trial was a phase II, where 64 castrate resistant with bone metastasis patients received ${ }^{223} \mathrm{Ra}$ a dose of $50 \mathrm{kBq} / \mathrm{kg}$ (33 patients) or placebo (31 patients) every 4 weeks. Primary endpoints were change in bone-alkaline phosphatase (ALP) concentration and time to skeletal-related events (SREs). Secondary endpoints included toxic effects, time to prostate-specific-antigen (PSA) progression, and overall survival. Both groups received external beam radiation therapy to painful areas. There were a statistically significant change in bone ALP and PSA response but not in time to SRE's and overall survival, as far as toxicity, the only significant difference includes more constipation in ${ }^{223} \mathrm{Ra}$ arm [62]. The above reported results warranted further evaluation of the product in a phase 3 trial.

ALSYMPCA is the first phase 3 randomized trial of an alpha emitter. The abstract was first presented at the $2011 \mathrm{ECCO} / \mathrm{ESMO}$ meeting which involved 922 castrate-resistant bone-metastatic prostate cancer patients recruited between June 2008 and February 2011 [63]. All patients had at least two bone metastases by bone scintigraphy and no visceral disease. Patients must have either received docetaxel or thought to be unsuitable for or refused docetaxel. In a multicenter trial in Europe and the united states, investigators randomized the patients $2: 1$ to radium-223 at a dose of $50 \mathrm{kBq} / \mathrm{kg}$ intravenous or placebo, in addition to standard care, stratified by prior docetaxel use, baseline alkaline phosphatase level, and current bisphosphonate use. Each patient randomized to the alpha pharmaceutical received six injections, one every four weeks. The primary endpoint was overall survival. Secondary endpoints include skeletal related events (SRE's) and a variety of safety-focused endpoints. A pre-planned interim analysis occurred after 314 deaths. At that point, the data revealed an overall survival hazard ratio of 0.695 in favor of the radium-223 arm $(\mathrm{P}=0.00185)$ and the trial was stopped by the data monitoring committee. Median overall survival was 14.0 months in the study arm and 11.2 months in the placebo arm. Time to first SRE was also improved (13.5 vs. 8.4 months; $\mathrm{HR}, 0.61 ; \mathrm{P}=0.0005)$. Hematologic toxicity consisted of neutropenia in $4 \%$ of patients ( $2 \%$ grade $3-4$ ) and thrombocytopenia in $8 \%$ ( $4 \%$ grade $3-4)$. The most common non-hematologic toxicities were bone pain (43 with radium-223 versus $58 \%$ in the placebo group), diarrhea (22\% versus $13 \%$ ), nausea ( $34 \%$ versus $32 \%$ ), vomiting ( $17 \%$ versus $13 \%$ ), and constipation (18\% in both groups). Grade 3-4 bone pain affected $18 \%$ of the radium-223 group and $23 \%$ of the placebo arm. Other grade 3-4 toxicities were uncommon [63]

\section{Conclusion}

The alpha particle emitting radionuclides potentially provide a novel approach to tumor treatment. Thus far the most promising benefit appears to be in patients with skeletal metastasis using the calcium-mimetic ${ }^{223} \mathrm{Ra}$. Radioimmunotherapeutic conjugates or conjugates with newer targeted nanoparticles may provide additional approaches to both hematologic and solid tumors. The use of ${ }^{223} \mathrm{Ra}$ will soon be reviewed with fast-track status by the FDA and this agent is likely to offer practice-changing patterns of care in the near future.

\section{References}

1. Quinn S (1995) Marie Curie: A Life. Simon and Schuster, New York.

2. Curie $P$, Curie $M$, Bemont $M G$ (1898) A new highly radio-active substance contained in the pitchbelnde. C R Acad Sci 127: 1215-1217.

3. Schales F (1978) Brief History of Ra-224 Usage in Radiotherapy and Radiobiology. Health Phys 35: 25-32.

4. Macklis RM (1993) The great radium scandal. Sci Am 269: 94-99. 
Citation: Sartor O, Maalouf BN, Hauck CR, Macklis RM (2012) Targeted use of Alpha Particles: Current Status in Cancer Therapeutics. J Nucl Med Radiat Ther 3:136. doi:10.4172/2155-9619.1000136

5. Bertrand A, Legras B, Martin J (1978) Use of radium-224 in the treatment of ankylosing spondylitis and rheumatoid synovitis. Health Phys 35: 57-60.

6. Baserga R, Yokoo H, Henegar GC (1960) Thorotrast-induced cancer in man Cancer 13: 1021-1031.

7. Jurcic JG, Larson SM, Sgouros G, McDevitt MR, Finn RD, et al. (2002) Targeted alpha particle immunotherapy for myeloid leukemia. Blood 100: 1233-1239.

8. Sgouros G (2008) Alpha-particles for targeted therapy. Adv Drug Deliv Rev 60: $1402-1406$

9. Humm JL (1986) Dosimetric aspects of radiolabeled antibodies for tumor therapy. J Nucl Med 27: 1490-1497.

10. Wheldon TE, O'Donoghue JA (1990) The radiobiology of targeted radiotherapy. Int J Radiat Biol 58: 1-21.

11. Franken NA, Hovingh S, Ten Cate R, Krawczyk P, Stap J, et al. (2012) Relative biological effectiveness of high linear energy transfer a-particles for the induction of DNA-double-strand breaks, chromosome aberrations and reproductive cell death in SW-1573 lung tumour cells. Oncol Rep 27: 769-774.

12. Gadbois DM, Crissman HA, Nastasi A, Habbersett R, Wang SK, et al. (1996) Alterations in the progression of cells through the cell cycle after exposure to alpha particles or gamma rays. Radiat Res 146: 414-424

13. Mulford DA, Scheinberg DA, Jurcic JG (2005) The promise of targeted \{alpha\}particle therapy. J Nucl Med 46: 199S-204S.

14. Lorimore SA, Kadhim MA, Pocock DA, Papworth D, Stevens DL, et al. (1998) Chromosomal instability in the descendants of unirradiated surviving cells after alpha-particle irradiation. Proc Natl Acad Sci U S A 95: 5730-5733.

15. Allen BJ, Blagojevic N (1996) Alpha- and beta-emitting radiolanthanides in targeted cancer therapy: the potential role of terbium-149. Nucl Med Commun 17: 40-47.

16. Allen BJ, Goozee G, Sarkar S, Beyer G, Morel C, et al. (2001) Production of terbium-152 by heavy ion reactions and proton induced spallation. Appl Radiat Isot 54: 53-58.

17. Rizvi SM, Allen BJ, Tian Z, Goozee G, Sarkar S (2001) In vitro and preclinical studies of targeted alpha therapy (TAT) for colorectal cancer. Colorectal Dis 3: $345-353$.

18. Allen BJ, Rizvi S, Li Y, Tian Z, Ranson M (2001) In vitro and preclinical targeted alpha therapy for melanoma, breast, prostate and colorectal cancers. Crit Rev Oncol Hematol 39: 139-146.

19. Miederer M, Seidl C, Beyer GJ, Charlton DE, Vranjes-Duric S, et al. (2003) Comparison of the radiotoxicity of two alpha-particle-emitting immunoconjugates, terbium-149 and bismuth-213, directed against a tumorspecific, exon 9 deleted (d9) E-cadherin adhesion protein. Radiat Res 159 : $612-620$.

20. Larsen RH, Wieland BW, Zalutsky MR (1996) Evaluation of an internal cyclotron target for the production of $211 \mathrm{At}$ via the 209Bi (alpha,2n)211 at reaction. Appl Radiat Isot 47: 135-143.

21. Brown I, Mitchell JS (1998) The development of a [211AT]-astatinated endoradiotherapeutic drug: part IV--late radiation effects. Int J Radiat Oncol Biol Phys 40: 1177-1183.

22. McLendon RE, Archer GE, Garg PK, Bigner DD, Zalutsky MR (1996) Radiotoxicity of systematically administered [211At]astatide in B6C3F1 and $\mathrm{BALB} / \mathrm{c}$ (nu/nu) mice: a long-term survival study with histologic analysis. Int $J$ Radiat Oncol Biol Phys 35: 69-80

23. Link EM, Carpenter RN (1990) 211At-methylene blue for targeted radiotherapy of human melanoma xenografts: treatment of micrometastases. Cancer Res 50: 2963-2967.

24. Weber DA, Eckerman KF, Dillman LT, Ryman JC (1989) MIRD: Radionuclide Data and Decay Schemes. The Society of Nuclear Medicine, New York.

25. Atcher RW, Friedman AM, Hines JJ (1988) An improved generator for the production of 212Pb and 212Bi from 224Ra. Int J Rad Appl Instrum A 39: 283286.

26. Nicoline M, Mazzi U (1999) Therapeutic potential of alpha-emitters: Chemistry to biology to clinical applications. SGE Editorali, Padova, Italy.

27. Boll RA, Malkemus D, Mirzadeh S (2005) Production of actinium-225 for alpha particle mediated radioimmunotherapy. Appl Radiat Isot 62: 667-679.
28. Kaspersen FM, Bos E, Doornmalen AV, Geerlings MW, Apostolidis C, et al. (1995) Cytotoxicity of 213Bi- and 225Ac-immunoconjugates. Nucl Med Commun 16: 468-476.

29. Chappell LL, Deal KA, Dadachova E, Brechbiel MW (2000) Synthesis, conjugation, and radiolabeling of a novel bifunctional chelating agent for (225) Ac radioimmunotherapy applications. Bioconjug Chem 11: 510-519.

30. Davis IA, Glowienka KA, Boll RA, Deal KA, Brechbiel MW, et al. (1999) Comparison of 225actinium chelates: tissue distribution and radiotoxicity. Nuc Med Biol 26: 581-589.

31. Harrison GE, Carr TE, Sutton A, Rundo J (1966) Plasma concentration and excretion of calcium- 47 , strontium- 85 , barium- 133 and radium- 223 following successive intravenous doses to a healthy man. Nature 209: 526-527.

32. Howell RW, Goddu SM, Narra VR, Fisher DR, Schenter RE, et al. (1997) Radiotoxicity of gadolinium-148 and radium-223 in mouse testes: relative biological effectiveness of alpha-particle emitters in vivo. Radiat Res 147: 342 348.

33. Durbin PW, Asling CW, Jeung N, Williams MH, Post J et al. (1958) The metabolism and toxicity of radium-223 in rats. University of California Radiation Laboratory, Berkely, California, USA.

34. Henriksen G, Breistøl K, Bruland ØS, Fodstad $\varnothing$, Larsen RH (2002) Significant antitumor effect from bone-seeking, alpha-particle-emitting (223)R demonstrated in an experimental skeletal metastases model. Cancer Res 62 3120-3125.

35. Henriksen G, Fisher DR, Roeske JC, Bruland ØS, Larsen RH (2003) Targeting of osseous sites with alpha-emitting 223Ra: comparison with the beta-emitte 89Sr in mice. J Nucl Med 44: 252-259.

36. McLaughlin P, Grillo-López AJ, Link BK, Levy R, Czuczman MS, et al. (1998) Rituximab chimeric anti-CD20 monoclonal antibody therapy for relapsed indolent lymphoma: half of patients respond to a four-dose treatment program. J Clin Oncol 16: 2825-2833.

37. Osterborg A, Dyer MJ, Bunjes D, Pangalis GA, Bastion Y, et al. (1997) Phase II multicenter study of human CD52 antibody in previously treated chronic lymphocytic leukemia. European Study Group of CAMPATH-1H Treatment in Chronic Lymphocytic Leukemia. J Clin Oncol 15: 1567-1574.

38. Sievers EL (2001) Efficacy and safety of gemtuzumab ozogamicin in patients with CD33-positive acute myeloid leukaemia in first relapse. Expert Opin Biol Ther 1: 893-901.

39. Kreitman RJ, Wilson WH, Bergeron K, Raggio $M$, Stetler-Stevenson $M$ et al. (2001) Efficacy of the anti-CD22 recombinant immunotoxin BL22 in chemotherapy-resistant hairy-cell leukemia. N Engl J Med 345: 241-247.

40. Kaminski MS, Estes J, Zasadny KR, Francis IR, Ross CW, et al. (2000) Radioimmunotherapy with iodine (131)I tositumomab for relapsed or refractory B-cell non-Hodgkin lymphoma: updated results and long-term follow-up of the University of Michigan experience. Blood 96: 1259-1266.

41. Liu SY, Eary JF, Petersdorf SH, Martin PJ, Maloney DG, et al. (1998) Followup of relapsed B-cell lymphoma patients treated with iodine-131-labeled antiCD20 antibody and autologous stem-cell rescue. J Clin Oncol 16: 3270-3278.

42. Witzig TE, White CA, Wiseman GA, Gordon LI, Emmanouilides C, et al. (1999) Phase I/II trial of IDEC-Y2B8 radioimmunotherapy for treatment of relapsed or refractory CD20(+) B-cell non-Hodgkin's Iymphoma. J Clin Oncol 17: 37933803.

43. Matthews DC, Appelbaum FR, Eary JF, Fisher DR, Durack LD, et al. (1999) Phase I study of (131)l-anti-CD45 antibody plus cyclophosphamide and total body irradiation for advanced acute leukemia and myelodysplastic syndrome. Blood 94: 1237-1247

44. McDevitt MR, Sgouros G, Finn RD, Humm JL, Jurcic JG, et al. (1998) Radioimmunotherapy with alpha-emitting nuclides. Eur J Nucl Med 25: 1341 1351.

45. Macklis RM, Lin JY, Beresford B, Atcher RW, Hines JJ, et al. (1992) Cellula kinetics, dosimetry, and radiobiology of alpha-particle radioimmunotherapy: induction of apoptosis. Radiat Res 130: 220-226.

46. Taylor DM (1970) The metabolism of actinium in the rat. Health Phys 19: 411 418.

47. Deal KA, Davis IA, Mirzadeh S, Kennel SJ, Brechbiel MW (1999) Improved in vivo stability of actinium-225 macrocyclic complexes. J Med Chem 42: 29882992. 
Citation: Sartor O, Maalouf BN, Hauck CR, Macklis RM (2012) Targeted use of Alpha Particles: Current Status in Cancer Therapeutics. J Nucl Med Radiat Ther 3:136. doi:10.4172/2155-9619.1000136

48. Dahle J, Borrebaek J, Melhus KB, Bruland OS, Salberg G, et al. (2006) Initial evaluation of (227)Th-p-benzyl-DOTA-rituximab for low-dose rate alphaparticle radioimmunotherapy. Nucl Med Biol 33: 271-279.

49. Larsen RH, Borrebaek J, Dahle J, Melhus KB, Krogh C, et al. (2007) Preparation of TH227-labeled radioimmunoconjugates, assessment of serum stability and antigen binding ability. Cancer Biother Radiopharm 22: 431-437.

50. Gibson AD (2002) Phase III trial of a humanized anti-CD33 antibody (HuM195) in patients with relapsed or refractory acute myeloid leukemia. Clin Lymphoma 3: $18-19$

51. Sgouros G, Ballangrud AM, Jurcic JG, McDevitt MR, Humm JL, et al. (1999) Pharmacokinetics and dosimetry of an alpha-particle emitter labeled antibody: 213Bi-HuM195 (anti-CD33) in patients with leukemia. J Nucl Med 40: 19351946.

52. Rosenblat TL, McDevitt MR, Mulford DA, Pandit-Taskar N, Divgi CR, et al (2010) Sequential cytarabine and alpha-particle immunotherapy with bismuth213-lintuzumab (HuM195) for acute myeloid leukemia. Clin Cancer Res 16 5303-5311.

53. Heeger S, Moldenhauer G, Egerer G, Wesch H, Eisenmenger A, et al. (2001) Alpharadioimmunotherapy of B-lineage non-Hodgkin's lymphoma using $213 \mathrm{Bi}$ labelled anti-CD19-and anti-CD20-CHX-A "'-DTPA conjugates. Onkologie 24 72.

54. Søyland C, Hassfjell SP (2000) Survival of human lung epithelial cells following in vitro alpha-particle irradiation with absolute determination of the number of alpha-particle traversals of individual cells. Int J Radiat Biol 76: 1315-1322.

55. Abbas Rizvi SM, Sarkar S, Goozee G, Allen BJ (2000) Radioimmunoconjugates for targeted alpha therapy of malignant melanoma. Melanoma Res 10: 281289

56. Allen BJ, Raja C, Rizvi S, Li Y, Tsui W, et al. (2005) Intralesional targeted alpha therapy for metastatic melanoma. Cancer Biol Ther 4: 1318-1324.
57. Cordier D, Forrer F, Bruchertseifer F, Morgenstern A, Apostolidis C, et al (2010) Targeted alpha-radionuclide therapy of functionally critically located gliomas with 213Bi-DOTA-[Thi8,Met(O2)11]-substance P: a pilot trial. Eur J Nucl Med Mol Imaging 37: 1335-1344.

58. Abbas N, Heyerdahl H, Bruland OS, Borrebæk J, Nesland J, et al. (2011) Experimental $\alpha$-particle radioimmunotherapy of breast cancer using 227Thlabeled p-benzyl-DOTA-trastuzumab. EJNMMI Res 1: 18

59. Heyerdahl H, Krogh C, Borrebæk J, Larsen Å, Dahle J (2011) Treatment of HER2-expressing breast cancer and ovarian cancer cells with alpha particleemitting 227Th-trastuzumab. Int J Radiat Oncol Biol Phys 79: 563-570.

60. Zalutsky MR, Reardon DA, Akabani G, Coleman RE, Friedman AH, et al. (2008) Clinical experience with alpha-particle emitting 211At: treatment of recurrent brain tumor patients with $211 \mathrm{At}$-labeled chimeric antitenascin monoclonal antibody 81C6. J Nucl Med 49: 30-38.

61. Nilsson S, Larsen RH, Fosså SD, Balteskard L, Borch KW, et al. (2005) Firs clinical experience with alpha-emitting radium-223 in the treatment of skeletal metastases. Clin Cancer Res 11: 4451-4459.

62. Nilsson S, Strang P, Aksnes AK, Franzen L, Olivier P, et al. (2012) A randomized, dose-response, multicenter phase II study of radium-223 chloride for the palliation of painful bone metastases in patients with castration-resistant prostate cancer. Eur J Cancer 48: 678-686.

63. Parker C, Heinrich D, O'Sullivan JM, Fossa S, Chodacki A, et al. (2011) Overal survival benefit of radium-223 chloride (Alpharadin) in the treatment of patients with symptomatic bone metastases in castration-resistant prostate cancer (CRPC): A phase III randomized trial (ALSYMPCA).

64. Andersson H, Cederkrantz E, Bäck T, Divgi C, Elgqvist J, et al. (2009) Intraperitoneal alpha-particle radioimmunotherapy of ovarian cancer patients: pharmacokinetics and dosimetry of (211)At-MX35 F(ab')2--a phase I study. J Nucl Med 50: 1153-1160. 